\title{
Achieving Flex in the Inflexible: Dealing with Individual Differences in Highly Structured EFL Preparatory College Courses
}

\author{
Fatimah M. A. Alghamdi ${ }^{1} \&$ Sarah A. M. Alnowaiser ${ }^{1}$ \\ ${ }^{1}$ English language Institute, King Abdulaziz University (KAU), Jeddah, Saudi Arabia \\ Correspondence: Fatimah M. A. Alghamdi, English language Institute, King Abdulaziz University (KAU), \\ Jeddah, Saudi Arabia. E-mail: fmalghamdi@kau.edu.sa
}

Received: March 1, 2017 Accepted: May 20, 2017 Online Published: May 26, 2017

doi: 10.5539/elt.v10n6p151 URL: http://doi.org/10.5539/elt.v10n6p151

\begin{abstract}
This study explores a field-motivated concern among English as a Foregin Language (EFL) teachers at a college preparatory English language program. The course syllabus for this program is fixed and systematically paced over four, seven-week modules. Despite formal assessment measures that result in placing the learners into four levels of English language proficiency, it has been reported by teachers, that inside the classrooms, the learners are of varying degrees of language proficiencies and attitudes. This study utilized a focus group approach and case-study classroom observations to explore the extent to which teachers take any measures to address these variations in proficiency and affect in the classroom. Focus-group participant teachers showed a great deal of awareness of variations amongst students and expressed tendencies towards using teaching strategies that would address these variations. However, limitations of time and material, they reported, tend to hinder such efforts. Likewise, when observing two classrooms within the same context, the researchers identified some individual differences among teachers in terms of strategies that account for student individual differences in the classroom, but these strategies were limited in number and variation. It was concluded that in highly-structured courses, with fixed material and unified learning outcomes, there remains room for creating dynamic classroom practices that are sensitive and reactive to students' needs and interests. The study calls for a larger scale investigation of this topic and advocates teaching approaches that have the potential to compensate for the unified syllabus and structured pacing of the courses.
\end{abstract}

Keywords: EFL, college preparatory year, differentiated instruction, language assessment, Saudi Arabia

\section{Introduction}

\subsection{Rationale and Context of the Study}

The English Language Institute (ELI) at King Abdulaziz University (KAU) is a typical provider of English, EFL courses, similar to many others across institutions of higher education in Saudi Arabia. In fact, the Preparatory Year educational policy was enacted by the Ministry of Higher Education, starting in the year 2009, and in two years, it was implemented at all the governmental universities across the country. The new policy was intended to subject the first-year university students to intensive courses in English and the basic sciences; e.g., Information Technology, Statistics, and so on, with the English language courses taking about half the actual contact hours in students' weekly schedules. The English preparatory year courses are highly structured. The material is predetermined by the ELI academic committees, and the syllabus is unified across each of the four proficiency levels. Moreover, all the teachers have to follow a detailed pacing guide, and be prepared to cover certain amount of the syllabus at predetermined intervals, punctuated by quizzes, writing and speaking tests, mid-module and final exams. The tests and exams are unified too. In other words, i.e. the students in all class sections of the English courses work on exactly the same material and take the same tests. The aim is that this situation results in a unified approach in teaching. All the students should receive instruction in similar content and thus, have equal chances of passing the exam. This is particularly important because students' achievements in the preparatory year determine their chance of getting seats at KAU colleges and departments of their choice.

With tight timing, set material and defined pacing, teachers often find themselves with limited choices for varying their teaching approaches. The teachers find a systematic approach to delivering the subject matter. Typically, this is very dependent on the textbook. The teachers tend to go over the activities one by one, explain the concepts and do the exercises provided in the textbook. Such practices inherently do not discriminate among 
students' varying proficiency levels, interests, or learning styles and preferences. Teaching practices that are not geared towards considering each and every student's needs will probably not only result in low achievement, but will also impact students' motivation and involvement. Tomlinson and Kalbfleisch (1998) assert that unless they take individual differences into consideration, teachers' chosen approaches will rarely address learners' needs or serve their interests. In fact, a previous study on how remedial sessions are conducted in the same institutional setting as this study's, Alghamdi and Siddiqi (2016) found that a large portion of the success of remedial sessions was due to the simplification strategies remedial sessions' teachers used in their instruction. It was suggested that these strategies, which are probably the reason why low-achieving learners seek remediation, be implemented in regular classrooms.

The teaching methods that address students' diverse needs have been recognized and practiced under the strategic approach of differentiated instruction (DI). DI is based on social constructivism and multiple intelligences theories. Social constructivism was introduced by Vygotsky in 1978. It is a theory that emphasizes interactions and collaborations as tools for learning. Subban (2006) asserts that the engagement between teachers and students, meaningful instruction, scaffolding, and students' ability are essential elements of the contemporary education. The theory of multiple intelligences was introduced by Gardner (1993) to draw attention to the claim that intelligence is not a "single measurable unit" (Subban, 2006). Multiple intelligences mean opportunities for all students through multiple techniques (Green, 1999).

DI is one of the pedagogical approaches that place great emphasis on student stance in the process of learning. It takes account of students' readiness, interests, and learning profile. "Differentiation is widely understood to be an aspect of a teachers' professional, pedagogical competence, a shorthand for all the methods which teachers try to use within the classroom to enable each pupil to achieve the intended learning targets" (Burton, 2003, p. 43). Tomlinson believes that "differentiated classrooms support students who learn in different ways and at different rates and who bring to school different talents and interests" (Tomlinson, 2014, p. 13). In the English as a Second Language (ESL) or English as a Foreign Language (EFL) classroom, students differ in the way they learn the language because of variation in their levels of aptitude, motivation, readiness and interest, as well as in their learning profiles. According to Tomlinson (2014), teachers can differentiate their instruction to meet varying student needs by varying the content, the process, the product, and the environment of instruction.Much research has investigated students' diversity, with quite a number of studies supporting the efficacy of differentiated classroom instruction. However, there are still gaps in the research on teachers' perceptions about implementing strategies in their classrooms to address mixed ability levels. In our case, the gap we propose to fill is essentially context sensitive. As explained above, teaching English language at the ELI is by no means prototypical of ESL or EFL language classes in other language institutes, where teachers are typically able to select material and pace instruction and activities in a flexible manner. The restrictions on syllabus, material and assessment at the ELI leave little room for any modification to take place. Nevertheless, the teachers have to deal with a typical language classroom where the learners vary in their abilities and attitudes.

This study set out to answer two field-motivated queries: (1) Do teachers take any measures to address variations in learners' language proficiency and affect? (2) How do DI strategies manifest in an actual ELI classroom?

\subsection{Literture Review}

Those involved in academic careers, including foreign/second language teaching know not only that learners are of mixed abilities, but also that learners' different abilities and attitudes will affect the day-to-day ongoing of the teaching process and product. Student variations can include, but are not limited to, factors of language proficiency level, motivation, and academic skills. These different factors can pose a challenge in instruction and classroom activities. They can also pose a challenge when teachers attempt to assess students' progress and achievement (McQuarrie \& McRae, 2010). When high school graduates are admitted to universities, they enter with many different learning styles, preferences, and experiences. The one-size-fits-all classroom usually won't work for every one of them. Tomlinson and Kalbfleisch (1998) explained that students cannot all learn in a one-size-fits-all classroom because such a classroom aims for only one level of challenge.

Teachers' use of a one-size-fits-all approach suggests a lack of concern with students' individuality and uniqueness, even though the teachers may acknowledge the importance of tackling the challenge that this poses to students' achievement (Tomlinson \& Kalbfleisch, 1998). In the classroom teachers sometimes make use of limited instructional strategies to each lesson, in many cases because there is little time to cover the curriculum (Tomlinson \& Kalbfleisch, aforementioned). A further challenge is that it is hard for teachers to get and keep students' attention for the whole lesson. So how can they address this? Research has shown that teachers can get students' full attention by including them in the lesson plan, by presenting lesson content in different ways, 
relating the content to students' own experiences, working in pairs or in groups and other strategies that diferenciate content or delivery methods. Therefore, many researchers and educators assert the importance of implementing DI in classrooms (Tomlinson \& Kalbfleisch, 1998; Tomlinson, 2002a \& 2002b; Burton, 2003).

The goal of DI is to aid students' learning process and meet students' individual needs in ways that foster their success (Tobin and Tippett, 2013). There is a growing body of literature on DI (McQuarrie \& McRae, 2010; Curran, 2015; Affholder, 2003; Ordover, 2012; Burton, 2003). These researchers suggest that DI supports students' progress and achievement. DI supports the learning process of students by helping them to progress individually and in accord with their particular abilities (Tomlinson, 2000). For example, Curran, (2015) investigated whether DI could support students' academic success. The findings show that students themselves believe that DI increased their understanding, attributing this gain to use of modeling, guided practice, and designing in each lesson (Curran, 2015). Tobin and Tippett (2013) found that language learning progresses best when there is more opportunity in the classroom for students to practice. As well, a varied way of presenting information, more individual practice, and different instructional approaches have also proven effective (Tomlinson \& Kalbfleisch, 1998). In differentiated classrooms, all students work on a variety of learning tasks in different ways (Kronberg, et al., 1997). McQuarrie, and McRae (2010) study find that DI strengthen students' self-confidence and engagement, and becoming more self-directed learners. These authors reviewed study showed that DI is clearly successful because it creates the environment that has the possibilities to enhance students' learning. Therefore, it is crucial to use DI in order to meet the individual needs of each student by varying the content, process, product, and environment of instruction.

In addition, teachers' beliefs and awareness are key factors in how DI is implemented and practiced in a classroom. Van den Berg and Ros (1999) describe teachers' beliefs as "a response to new situations and/or changing demands" (p. 880 as cited in Nicolae, 2014). A qualitative study conducted by Affholder (2003) investigated changes in teachers' pedagogical processes when implementing DI in their classrooms. The findings showed evidence that DI strategies and components of strategies can be practiced in classrooms when teachers are aware of it. It also showed that teachers need more time to be able to implement all components of DI in their classrooms.

Applying DI in the classroom, however, is not always straightforward and challenge-free. Ordover (2012) conducted individuals and focus-group interviews, as well as an online questionnaire to explored teachers' perceptions of DI. The data were gathered using three. The findings revealed three challenges that teachers were facing. (1) They had insufficient understanding of DI principles and practice and they need more training; (2) DI can be overwhelming to manage in the classroom; and (3) implementing DI was difficult in the absence of support from administration and students, with the administration focusing only on the standardize test scores. In addition, implementing DI can be challenging for teachers because it requires them to think of new ways of varying instructions (Tobin and Tippett, 2014). This can be time-consuming. Other studies found that in many cases novice teachers, in particular, struggled with practicing DI in classrooms (Burton, 2003).

\section{Method}

A qualitative approach was decided to be appropriate to address the two exploratory questions of the study. A focus-group interview was employed to find out how the teachers in this particular context deal with mixed-ability learners and if they are aware of differentiated instruction strategies. In addition, two case-study observations were conducted to identify classroom practices that could indicate two ELI teachers' considerations of the individual differences in learners' abilities and attitudes. A Case-study focuses on participants, to recognize their perceptions of ideas and principles. "It highlights specific events that are relevant to the case" (Hitchcock \& Hughes, 1995, p. 317). According to Given (2008, p. xxix), "qualitative research is designed to explore the human elements of a given topic, where specific methods are used to examine how individuals see and experience the world." Wallen and Fraenkel (2001, p. 432) emphasized that qualitative research is "describing in detail all of what goes on in a particular activity or situation."

To obtain such qualitative data the classroom observations were carried out, the researchers developed an observation form that identifies teachers' utilization of differentiated instructional strategies. For example, the teacher use of Arabic language, use of multimedia, and restating book instructions in a simpler language. Some of the strategies were adopted from Tomlinson (2014), and modified to fit into the context of the study.

All the observed and the interviewed teachers were ELI female English language teachers with a minimum teaching experience of 10 years (with one exception). One observed teacher, however, was newly appointed with less than one year experience in teaching.

Heigham and Croker (2009, p. 166) state further that, "observation is the conscious noticing and detailed 
examination of participants' behavior in a naturalistic setting". An observation sheet will be used as a tool to help spot examples of techniques used by the teachers, as well as to evaluate teachers' practices. In addition, the interviews will be scheduled not more than one week after the observation. A digital recorder will be used to record the interviews. This will permit me to record all teachers' ideas and answers. After collecting the data, the interviews will be transcribed. Patterns and themes in the data will be coded using NVIVO $10 \circledR$ Software Package.

\section{Findings and Discusion}

The focus group and the two classroom observations provided data of exploratory nature. When the researchers set out to investigate the extent to which individual differences are addressed in the ELI's EFL courses, no previous knowledge was available to them about this particular context. A focus group interview was necessary to capture the general attitudes and awareness ELI teachers have about mixed ability classrooms, and the options that are there for teachers in dealing with them. After that case-study observations were also needed in order to find if any of previously determined strategies are used in the classroom.

\subsection{Focus Group}

The focus group was conducted to explore if the ELI teachers take any measures to address learners' linguistic and affective variations. The teachers were first asked three straightforward questions that are not loaded with any suggestions or ideas: (1) How can a teacher deal with mixed-ability classrooms? (2) How can a teacher deal with a task instruction that is difficulty for some of the students to understand? (3) What are the best ways to support students with different abilities? (4) How to assess students' varying degrees of progress?

The teachers were allowed enough time to answer each question before moving to the next. The researcher didn't intervene in the conversation's turn-taking, or in how much each teacher contributed.

The teachers immediately showed recognition of the problem of having students of varying levels in a classroom. They provided practical strategies. The first set of these strategies was related to grouping the students. Teachers seem to group the students using three different strategies. The first strategy is to group the students on the basis of their different proficiency levels. "I put the weaker ones with the stronger ones ... because usually the stronger ones would help the weaker students and the weaker students feel safer with the stronger students because they can always refer to them," said PA. The second strategy is grouping the students based on their needs PB explained that she pre-tests students before grouping them: "small test to see how good they are....So, you can group them ... at least you have a better idea about them so you can tailor the program since the beginning about how you are going to deal with them." Finally, there is grouping by students' choice. PB explained that she let students choose their groups: "so you can ask them to group themselves. To see weather, they like this group or not."

All the three teachers reported using what is known as flexible grouping. In normal grouping teachers may chose to place the students in groups according to where they sit, with those who sit next to them. This way is completely unresponsive to who would work better with who. Such grouping will probably lead to placing the wrong students together. For example, two students who are both unmotivated to work on an activity would sit together doing nothing, or too little, about the task. In flexible grouping the teachers forms groups of students according to their abilities and interests. Flexible grouping has been identified as a DI strategy. It is essential for interaction that leads to developing new content and new ideas (Tomlinson, 2001). In Melesse (2015), flexible grouping was found to be one of the most recognized instructional strategies amongst teachers besides "independent study" and "interest centers." The participants of this study reported using flexible grouping mainly to allow interaction between high-achieving and low-achieving students, but at least one of them extended this flexibility in grouping to situations when these two groups of students should be separated.

The second set of strategies of dealing with mixed-ability classrooms is related to instructional adjustment. These adjustments included use of Arabic (students' first language), simplifying instructions, and giving examples to clarify instructions. Participant PC reported that she let the students speak in Arabic to communicate easily and feel safe:

"I let them speak in Arabic like how much you save in your allowance. She speaks in Arabic and she goes and ... the class goes in discussion and they laugh together and the class becomes a different thing ... because it is a language and medium of communication, they know how to speak".

Participant PA goes further and asserts that even grammar rules can be explained in Arabic: "sometimes you can explain even some grammar points or some vocabulary in the native tongue. This is promoted by research." Teachers also stated that they simplify the instructions for students to understand and be engaged in the class. PC 
explained that: "sometimes you need to change the instructions, the language, the way you simplify instructions to make them [the students] all engage." Also, she defined differentiated instructions as a way to simplify the instructions: "differentiated instruction is simply lenient simplifying, accommodating instructions for the whole students in the class." A third instructional adjustment strategy reported by the participant teachers is giving examples. Examples PB asserts help weaker students in understanding, and in their motivation:

You need to demonstrate the task for them giving them an example not only one, two or more if they did not understand. They need to understand the task first because some people ... they are demotivated by that ... this distorts their self image if they do not understand.

Instructional strategies include using tiered assignments, where teachers assign tasks of varied degrees of difficulty of the same activity. There was only one mention of such a strategy amongst our focus-group participants. PB explained that she uses assignments that vary in their difficulty, but she does not let the students know that she is expecting different product from them:

... Write a critical review about something, for good students, but for weak students watch the YouTube about different kinds of food in ... and you can write a paragraph about it ... but good students are not going to write one paragraph only ... and they email me so that ... developing their language ability without .. It's writing ... weak: you can give them something more to develop, but I don't want weak students to feel that about themselves, because that will make them de-motivated and also will distort their image.

The participants demonstrated awareness of different students' needs. They reported using technology, varying the pace of time, building students self efficacy, and believing in the differences between students to support students learning. PB explained that she encourages her students to use the technology: "... but if they do not know the information, we can work together. We Google it." Also, she varies the pace of learning for different students' needs: "if we do not have time I ask them to go home and search this information so they have better understanding." PA notes that students are not the same, and that teachers have to consider this: "students are different. They have different capabilities, IQs, so we need to put that into consideration and to come up with task or exercises that account for their needs and also IQs." Moreover, teachers showed consideration of students' feelings and attitudes, relating these to motivation. PB explained:

"sometimes I assign, at the beginning, the best students to talk, to be the head of that group, in order to just show others how to speak and how to organize, but then I allow also the low achiever students to take the lead because they need to believe in themselves. I need to motivate them to speak and to do some tasks."

Alghamdi and Siddiqui (2016) had called for affective support for the students at this particular context. They argued that low-achieving students resort to remedial classes to seek such support, and that: "A positive change can be promoted by raising, through training, teachers' awareness of the affective side of the EFL learning process and by taking measures to address learners fears and insecurities (p. 212)".

Another strategy the participant teachers introduced, in the focus group interview, was assessment. They reported using strategies for pre-assessing students, checking for their understanding, and post assessing them for evaluation. PB believes that she has to pre-assess students before grouping them: "I give small test to see how good they are." She also mentioned that ongoing assessment is a must "you need to check their understanding." Finally, post-assessment is used to evaluate students' understanding. PB explained "for the foundation year maybe by the end of each class you have the freedom to come up with pop quizzes, small quizzes, so you can check their understanding. It doesn't mean that they need to answers two pages... [just] core questions to check their understanding." Also PC mentioned that she gives exercises to check their development.

I usually ... after I finish ... like three units ... They have to have exercises on the board. They have to write on the board, so I put sentences, and they have to fill in the blanks or make a choice ... just like the same materials in the quizzes but they have to do it on the board"

However, the teachers spoke about the limitations of dealing with mixed ability classrooms. PA said:

You don't have the time for that ... you train them on certain things because you really want them to pass the test ... there is a difference between teaching for a test and teaching general English. That's the problem. We don't have the luxury ... actually the target here is not communication the target here is passing the test pasting level 1 and then level 2 and then level 3 and then level 4 in one and a half months for every level.

In Prince's (2011) study, teachers indicated that class size and lack of training were the main barriers for DI implementation. Although class size is quite big (25-30 students), the teachers did not comment on that, nor did they comment on lack of training on DI strategies. 
The three teachers spoke about the weaker students, saying that they need special type of remedial instruction, where they will not need to study the book of the course they have failed for a second time. They also related to the books and how "culturally loaded" they are. This awareness of content suitability is very relevant to DI concepts. The teachers are indirectly calling for a change in the course material so that it conforms to the cultural predisposition of the students.

\subsection{Classroom Observation}

One of the researchers observed two classrooms as case-study approach. A predefined list of strategies was developed to explore the extent to which the teachers show consideration of learners' different abilities and attitudes (Table 1). These strategies were adopted from Tomlinson's (2014), but were modified to fit the context of the study. They were classified into three aspects of classroom practice: (i) the learning environment and content, (ii) Instructions and Instructional strategies, and (iii) ongoing assessment. The strategies were enlisted in a column in an observation sheet with a number of adjunct columns to record instances of strategy occurrences. 49 instances of strategy use were recorded in both classrooms. The majority of these were pertaining to learning environment and content.

Table 1. Observed differentiating strategies

\section{Learning environment and materials}

Whole classroom unrestricted interaction

Providing background knowledge and past experience.

Classroom routine corresponds to task requirements.

Providing visual aids (electronic).

Using videos and audios.

Varying the pace of the activity (Flexible use of time).

Providing checklists and modeling.

Allowing students to use technology.

Using higher level tasks (e.g. applying, analyzing)

Providing iconic token

Giving students the choice of activities.

Guiding students who need assistance (individually).

Flexible grouping (regrouping Ss, or choice to work alone).

\section{Instructions and instructional strategies}

Repeating instructions.

Using hand signals, gesture

Simplifying (modifying) instruction.

Giving step by step instruction.

Using Arabic to clarify.

Writing on Whiteboard (unplanned).

Using different colors on Whiteboard.

Using graphic organizer.

Different tasks to different students (tiered activity).

Having Students to move around.

\section{Ongoing assessment}

Monitoring process and ongoing assessment

Post assessment. 
The two teachers recorded 28 instances of the learning environment and content related differentiating strategies annotated in the observation sheet. The most frequently used strategy was 'whole classroom unrestricted interaction', wherein the teacher allowed the classroom interaction to respond to certain activity outcome or to change pace as a reaction to learners' comments or questions. The differentiating strategy that comes next in frequency was 'Providing background knowledge and past experience'. In four instances the observed teachers related to past knowledge or experience in order to clarify a language form or usage.

'Adjusting classroom routine to correspond to task requirements', 'providing visual aids (electronic)', 'using videos and audios' and 'varying the pace of the activity (Flexible use of time)' are all differentiating strategies that came third in the strategies' order of frequency. Each of these four strategies was identified three times.

It is recorded that the teachers used higher level tasks when teaching. They provided 'checklists' and 'models', and allowed the students to use 'technology' to support their learning. However, 'giving students a choice,' 'flexible grouping,' and 'providing an iconic tokens' were not utilized at all in the observed classes.

It was recorded that teachers used 18 instances of the differentiated instructional strategies. The most used strategy was 'repeating instructions for students to understand'. 'Using graphic organizer', 'tiered activity', and 'letting students move around' strategies were not observed in the two classes. It was also frequently recorded that teachers used their 'hand signals and gestures' as well as 'simplified instructions' for students to understand. When students were confused, teachers gave a step by step instruction and used 'Arabic' to clarify. Finally, teachers used the whiteboard to explain unplanned questions, and they used different colors. All of this provides evidence that teachers vary their teaching practice to cater for different abilities and learning styles.

For the ongoing assessment, it was observed that teachers occasionally monitor the progress of students during lessons. However, no evidence was seen of post-assessment. This conforms to Melesse' (2015) findings that assessment was the least practice teachers apply differentiation to.

Classroom observation showed that teachers used a number of practices and strategies that show their appreciation of the individuality of the learners. They provided background knowledge and past experiences when explaining a concept to students. It was observed that students followed flexible routine when they work in a task, and that teachers provided electronic visual aids as well as videos and audios for students. Teachers were flexible in the time to give students of different abilities the chance to pace their learning. In short the observed teachers employed a large number of instructional strategies of DI nature, but they were lacking in tiered activities and assessment strategies, both pre-assessment and ongoing assessment strategies. This goes in line with Bailey and Williams-Black (2008) who showed that teachers varied activities to motivate students, differentiating through content and process, but they did not differentiate through product, i.e. assessment outcome.

\section{Conclusions and Implications for Teaching and Further Research}

This study addresses field-specific issues in mixed ability classrooms. The courses in this context are too inflexible in terms of content and time to allow for individualized instruction. DI approach, which would ideally be the appropriate approach in such an educational setting, was assumed to provide little help in this regard, as course content and pacing of content delivery are highly structured. However, the focus group interview has shown otherwise. The teachers could find ways to adjust and modify content and instructional practices such that they serve a wide range of learners. Focus group participants showed high level of awareness and concern for variation in students' levels of proficiency and skills. They reported on a number of strategies to address this variation, including simplifying instruction, giving the weaker students extra lessons and use of Arabic language. However, concern was expressed about time limitations, limitations in assessment and the compulsory course books.

Assessment was found to be the weak aspect in any attempt to tailor classroom instruction to suit students' level of proficiency, interests and needs. In a quick-paced, structured language classes the teachers will have no choice but to address one concern, which is passing the exams. Classroom observations yielded similar results. Teachers do implement a number of DI strategies in their classroom, but since they lack control over formal exams, they show no evidence of differentiating assessment in the classrooms.

Further research on DI in this context will yet need to be carried out with more teachers with varying degrees of experience. The case-study scope of this study has limited the potential for interpretation and generalization of findings, but has, on the other hand, explored the grounds of dealing with mixed-ability classrooms,

This study is also limited by both general and context-related focus-group limitations. Since the participants belong to the same workplace and are discussing field-specific problem openly, they may intentionally or 
unintentionally drift into speaking about what they perceive as ideal, instead of what actually takes place in day-to-day classrooms. Also, when colleagues discuss work issues together, they tend to inspire each other with ideas, which might mask their real opinions.

\section{References}

Affholder, L. P. (2003). Differentiated instruction in inclusive elementary classrooms (Doctoral dissertation). Retrieved from ProQuest Dissertations \& Theses Global. (305318471).

Alghamdi, F. M. A., \& Siddiqui, O. (2016). Supporting Low-achieving EFL Learners: Expectations, Procedure and Significance of Remedial Sessions at a Saudi University. Journal of Education and Training Studies, 4(12), 204-212. https://doi.org/10.11114/jets.v4i12.2028

Bailey, J. P., \& Williams-Black, T. H. (2008). Differentiated instruction: Three teachers' perspectives. College reading association yearbook, 29, 133-151.

Burton, D. (2003). Differentiation of schooling and pedagogy. In S. Bartlett, \& D. M. Burton (Eds.), Education studies: essential issues (pp. 42-71). London: Thousand Oaks, Calif: SAGE Publications Ltd. https://doi.org/10.4135/9781446215043.n3

Curran, M. A. (2015). The impact of differentiated instruction for diverse learners (master's thesis). Retrieved from ProQuest Dissertations \& Theses Global. (1783102756).

Gardner, H. (1993). Multiple intelligences: the theory in practice (Reprinted.). New York: Basic Books.

Green, F. R. (1999). Brain and learning research: Implications for meeting the needs of diverse learners. Education, 119(4), 682-688.

Heigham, J., \& Croker, R. (Eds.). (2009). Qualitative research in applied linguistics: A practical introduction. Springer. https://doi.org/10.1057/9780230239517

Hitchcock, G., \& Hughes, D. (1995). Research and the Teacher (second edition). London: Routledge

Kronberg, R., York-Barr, J., Arnold, K., Gombos, S., Truex, S., Vallejo, B., \& Stevenson, J. (1997). Differentiated teaching \& learning in heterogeneous classrooms: strategies for meeting the needs of all students. Retrieved from http://eric.ed.gov/?id=ED418538

McQuarrie, L. M., \& McRae, P. (2010). A provincial perspective on differentiated instruction: The Alberta Initiative for School Improvement (AISI). Journal of Applied Research on Learning, 3(4), 1-18.

Melesse, T. (2015). Differentiated instruction: Perceptions, practices and challenges of primary school teachers. Science, Technology and Arts Research Journal, 4(3), 253-264. https://doi.org/10.4314/star.v4i3.37

Nicolae, M. (2014). Teachers' beliefs as the differentiated instruction starting point: Research basis. Procedia-Social and Behavioral Sciences, 128, 426-431. https://doi.org/10.1016/j.sbspro.2014.03.182

Ordover, A. (2012). Teacher perceptions of differentiated instruction (Doctoral dissertation). Available from ProQuest Dissertations \& Theses Global. (1146589662).

Prince, B. L. (2011). Teacher perceptions of differentiated instruction (Doctoral dissertation). Retrieved from ProQuest Dissertations \& Theses Global. (879043001).

Subban, P. (2006). Differentiated instruction: A research basis. International education journal, 7(7), 935-947.

Tobin, R., \& Tippett, C. D. (2014). Possibilities and potential barriers: Learning to plan for differentiated instruction in elementary science. International Journal of Science and Mathematics Education, 12(2), 423-443. https://doi.org/10.1007/s10763-013-9414-z

Tomlinson, C. A. (2000). Differentiation of instruction in the elementary grades. ERIC Digest. Retrieved from https://eric.ed.gov/?id=ED443572

Tomlinson, C. A. (2001). How to differentiate instruction in mixed-ability classrooms. ASCD.

Tomlinson, C. A. (2002a). Invitations to learn. Educational leadership, 60(1), 6-11.

Tomlinson, C. A. (2002b). Different learners different lessons. Instructor (1999), 112(2), 21-26+. Retrieved from https://search.proquest.com/docview/224394934?accountid $=142908$

Tomlinson, C. A. (2014). The differentiated classroom: responding to the needs of all learners (2nd ed.). Alexandria, VA: Association for Supervision \& Curriculum Development.

Tomlinson, C. A., \& Kalbfleisch, M. L. (1998). Teach me, teach my brain: A call for differentiated classrooms. 
Educational Leadership, 56(3), 52-55.

Van Den Berg, R., \& Ros, A. (1999). The permanent importance of the subjective reality of teachers during educational innovation: A concerns-based approach. American Educational Research Journal, 36(4), 879-906. https://doi.org/10.3102/00028312036004879

Vygotsky, L. S. (1978). Mind in society: the development of higher psychological processes. Edited by Michael Cole. Harvard University Press.

\section{Copyrights}

Copyright for this article is retained by the author(s), with first publication rights granted to the journal.

This is an open-access article distributed under the terms and conditions of the Creative Commons Attribution license (http://creativecommons.org/licenses/by/4.0/). 